\title{
SECAGEM COMBINADA CONVECTIVO-SOLAR DE RESÍDUO ENRIQUECIDO DE CASCA DE ABACAXI
}

\author{
L. F. MONTEIRO' ${ }^{1}$, O. L. S. ALSINA ${ }^{2}$, G. F. SILVA ${ }^{3}$, J. O. R. SANTOS ${ }^{4}$, J. V. A. JARDIM ${ }^{4}$, A. S. \\ SILVA $^{1}$, K. M. M. LEÃO ${ }^{5}$ \\ ${ }^{1}$ Universidade Federal de Sergipe, Núcleo de Engenharia de Produção \\ ${ }^{2}$ Universidade Tiradentes, Instituto de Tecnologia e Pesquisa \\ ${ }^{3}$ Universidade Federal de Sergipe, Departamento de Engenharia de Petróleo \\ ${ }^{4}$ Universidade Federal de Sergipe, Departamento de Engenharia Mecânica \\ ${ }^{5}$ Instituto Tecnológico e de Pesquisa do Estado de Sergipe, Laboratório de Bromatologia

\section{E-mail para contato: lucianofm2007@gmail.com}

\begin{abstract}
RESUMO - Resíduos oriundos de frutas podem ser aproveitados para a produção de suplementos através do enriquecimento proteico por crescimento celular. Neste trabalho foi estudada a secagem de resíduo de abacaxi enriquecido por Saccharomyces cerevisiae em biorreator-secador convectivo solar, com finalização em secador convectivo de bandejas. A casca triturada de abacaxi foi enriquecida com 3\% de inóculo de Saccharomyces cerevisiae durante $24 \mathrm{~h}$ a $30{ }^{\circ} \mathrm{C}$ com aeração. O produto enriquecido foi submetido a secagem solar, com temperatura entre $32{ }^{\circ} \mathrm{C}$ e $40{ }^{\circ} \mathrm{C}$, seguida de secagem convectiva. A secagem foi finalizada em secador convectivo de bandejas, com temperatura de $60{ }^{\circ} \mathrm{C}$. O produto apresentou índice de enriquecimento proteico em torno de 4,2 na base seca; dependendo das condições de processo é possível obter um enriquecido proteico com umidade final inferior a $12 \%$, compatível com o exigido pelas normas para esse tipo de produto. As curvas de secagem foram ajustadas por modelo de primeira ordem, de modo a obter parâmetros necessários para uma posterior simulação do processo.
\end{abstract}

\section{INTRODUÇÃO}

O abacaxi, proveniente de planta tropical e subtropical, é largamente produzido no Brasil, com destaque aos estados da Paraíba, Pará e Minas Gerais, em que juntos foram responsáveis por $51 \%$ da produção no país em 2012, e que colocam o Brasil como um dos grandes produtores mundiais desse fruto (IBGE, 2012). As indústrias de produtos alimentícios produzem grande quantidade de resíduos com alta capacidade de reutilização. $\mathrm{O}$ aproveitamento desses subprodutos traz benefícios como agregar valor e reduzir os impactos ambientais causados pela deposição inadequada. Dentre os possíveis fins para os resíduos de abacaxi está sua utilização como suplemento para alimentação animal. A casca de abacaxi, por si só, não apresenta teor de proteína adequada para a alimentação animal nem uma vida útil conveniente para tal fim. Logo, é necessário processá-la de modo a obter um enriquecimento e vida útil prolongada. $\mathrm{O}$ enriquecimento proteico pode ser feito utilizando-se microrganismos, para processo de crescimento celular; a vida útil dos alimentos, por sua vez, pode ser prolongada por métodos de 


\section{9 a 22 de outubro de 2014 \\ Florianópolis/SC}

secagem (Campos et al., 2005; Alexandre et al., 2013; Fellows, 2000). O microrganismo Saccharomyces cerevisiae, um dos melhores fornecedores de proteína, não apresenta características patogênicas e pode ser utilizado como alimento humano e animal (Procreatin, 2006). Esta espécie possui organismo microscópico de célula única, viva e tem as mesmas funções de qualquer outro ser vivo, respira, alimenta-se, excreta (Rodrigues, 2001; Rocha, 2002). A eficiência da conversão proteica por leveduras depende de fatores como: temperatura, suprimento de oxigênio, disponibilidade de nutrientes. A fermentação semissólida (FSS), definida como um crescimento de microrganismos em material sólido é utilizada industrialmente por apresentar algumas vantagens, como menor geração de efluentes, diminuição do risco de contaminação do meio, menor exigência de água quando comparada a fermentação submersa e baixo investimento (Pandey et al., 2001; Santos, 2006).

Este trabalho consiste em obter do bagaço resultante da extração do suco do abacaxi um concentrado proteico seco para suplemento em formulações de ração mediante enriquecimento com Saccharomyces Cerevisiae, seguida de secagem em biorreator-secador convectivo-solar, com finalização em secador convectivo de bandejas.

\section{MATERIAIS E MÉTODOS}

\subsection{Matéria prima}

Os abacaxis foram adquiridos no mercado da cidade de Aracaju e conservados sob refrigeração a $8{ }^{\circ} \mathrm{C}$ para uso posterior. Para a preparação das amostras, foram lavados com água corrente e triturados em processador. $\mathrm{O}$ bagaço resultante foi armazenado em freezer a $-18{ }^{\circ} \mathrm{C}$, por períodos inferiores a 50 dias, até sua utilização nos experimentos. Para o enriquecimento pelo método de FSS foi utilizada levedura Saccharomyces Cerevisiae comercial seca, com 50\% de proteínas.

Os experimentos foram realizados no Laboratório de Tecnologias Alternativas, LTA, da UFS e as análises físicas e químicas no Laboratório de Bromatologia do Instituto Tecnológico e de Pesquisa do Estado de Sergipe - ITPS.

\subsection{Equipamentos}

O equipamento utilizado cumpre a dupla função de biorreator e secador. Consta de espaço para as bandejas com as amostras e possui 7 exaustores que geram a circulação de ar através do bagaço de abacaxi. A tampa na parte superior é de vidro para a operação como secador sola

O enriquecimento foi realizado em bandejas, pela técnica de FSS, com aeração, de modo a melhorar o suprimento de oxigénio. Em todos os experimentos foi inoculado 3\% de levedura, em relação à massa de substrato, permanecendo durante $24 \mathrm{~h}$ a $30^{\circ} \mathrm{C}$. $\mathrm{O}$ bagaço de abacaxi enriquecido foi seco mediante processos combinados, visando a melhor qualidade do produto. As etapas de secagem foram: solar com aeração, seguida de convectiva no biorreator secador a baixa temperatura e finalizando em secador convectivo de bandejas com circulação forçada de ar a $60{ }^{\circ} \mathrm{C}$.

Após a secagem as amostras foram colocadas em embalagens vedadas e identificadas e 


\section{9 a 22 de outubro de 2014 \\ Florianópolis/SC}

encaminhadas para análise. As análises realizadas e métodos utilizados constam na Tabela 1. Além dos ensaios mostrados na Tabela 1, foram determinados mediante cálculo, o valor energético e o teor de carboidratos.

Tabela 1 - Análises realizadas e métodos utilizados

\begin{tabular}{l|l|l|l|l|l|l|l}
\hline $\begin{array}{l}\text { Gorduras } \\
\text { Totais }\end{array}$ & $\begin{array}{l}\text { Umidade } \\
(\%)\end{array}$ & $\begin{array}{l}\text { RMF* }^{*} \\
\text { Cinzas }\end{array}$ & $\begin{array}{l}{ }^{\circ} \text { Brix a } \\
20{ }^{\circ} \mathrm{C}\end{array}$ & $\begin{array}{l}\text { Açúcares } \\
\text { Totais }\end{array}$ & $\begin{array}{l}\text { Açúcares } \\
\text { Redutores }\end{array}$ & $\begin{array}{l}\text { Açúcares } \\
\text { Invertidos }\end{array}$ & Proteínas \\
\hline \multicolumn{7}{c|}{ IAL 2005 } \\
\hline $032 / \mathrm{IV}$ & $012 / \mathrm{IV}$ & $018 / \mathrm{IV}$ & $315 / \mathrm{IV}$ & $138 / \mathrm{IV}$ & 31051 & 31037 & \multirow{2}{*}{ Kjeldahl } \\
\hline
\end{tabular}

* Resíduo Mineral Fixo (Cinzas)

\section{RESULTADOS E DISCUSSÕES}

\subsection{Secagem combinada-solar convectiva}

Os resíduos de abacaxi, enriquecidos conforme a metodologia relatada, foram submetidos a secagem combinada solar-convectiva mudando os tempos e as condições de operação. As Figuras 1a e $1 \mathrm{~b}$ mostram as curvas de secagem combinada solar-convectiva, sob a forma de umidade na base úmida em função do tempo $\left(X_{b u} \%\right.$ vs t) para duas condições diferentes de operação realizadas em duplicata e triplicata, respectivamente. Observa-se em ambas as Figuras que houve uma boa reprodutibilidade, apesar da variabilidade e heterogeneidade inerentes ao tipo de material estudado.

A Figura 1a apresenta os resultados de secagem em três etapas: solar, com temperatura variando entre $37^{\circ} \mathrm{C}$ e $39^{\circ} \mathrm{C}$; convectiva com circulação forçada a temperatura ambiente de $30^{\circ} \mathrm{C}$ e finalização com convectiva forçada de curta duração, $90 \mathrm{~min}$, a $60^{\circ} \mathrm{C}$. A última etapa, além de finalização da secagem, teve como objetivo a inativação da levedura. Neste processo combinado, com duração total de 1400 min, obtiveram-se produtos enriquecidos com baixo nível de umidade, inferior a 10\%.

$\mathrm{Na}$ Figura 1b são apresentadas as curvas de secagem realizada em duas etapas: solar a $32{ }^{\circ} \mathrm{C}$ e convectiva forçada a $60{ }^{\circ} \mathrm{C}$. Neste processo combinado, com duração total de 308 min, o produto enriquecido foi seco até níveis de umidade ainda elevados, de $68 \%$ na base úmida, pelo que seria necessária uma etapa de finalização adicional. Observa-se que para este processo combinado, as duas etapas encontram-se bem diferenciadas, com taxa de secagem mais elevada durante a fase convectiva.

Para um melhor entendimento das Figuras 1, 2 e 3, bem como das Equações 1, 2, e 3 aqui apresentadas, será descrita uma breve nomenclatura: $X$ representa a umidade; $X^{*}$ é a razão de umidade; $X_{b u}$ e $X_{b s}$, umidade na base úmida e na base seca respectivamente; $X_{\infty}$ é a umidade de equilíbrio, $X_{i}$ é a umidade inicial; $k, k_{1}$ e $k_{2}$ são as constantes de secagem em $\min ^{-1}$, nos modelos representados pelas Equações 1, 2 e 3 e t é o tempo em min. 


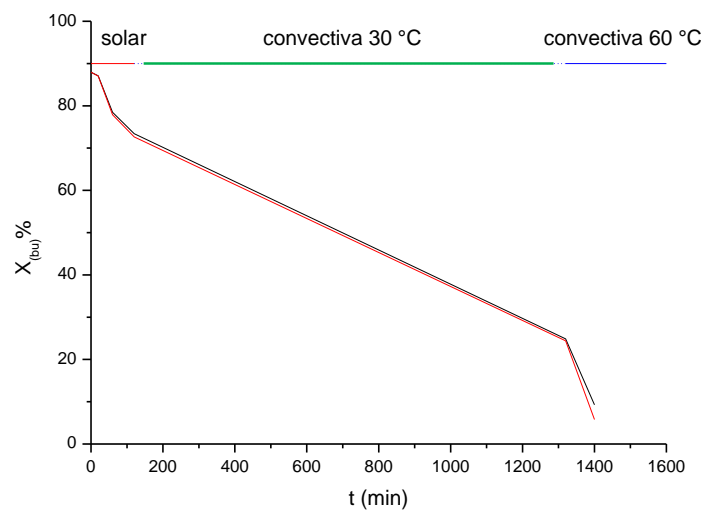

(a)

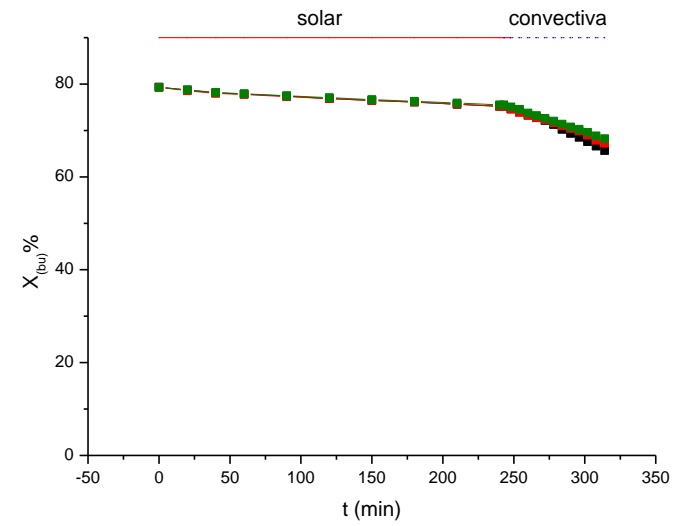

(b)

Figura 1 - Secagem combinada solar-convectiva.

(a) Secagem solar $\mathrm{T}=39^{\circ} \mathrm{C}$. Secagem convectiva $\mathrm{T}=30^{\circ} \mathrm{C}$. Secagem convectiva $\mathrm{T}=60^{\circ} \mathrm{C}$ (b) Secagem solar $\mathrm{T}=32^{\circ} \mathrm{C}$. Secagem convectiva com circulação forçada $\mathrm{T}=60^{\circ} \mathrm{C}$.

\subsection{Modelagem das curvas de secagem}

Na Figura 2 observa-se que a secagem combinada constando de três etapas, solar, convectiva com circulação forçada a $30{ }^{\circ} \mathrm{C}$ e finalização com secagem convectiva de curta duração a $60{ }^{\circ} \mathrm{C}$, pode ser representada com boa aproximação por uma única curva de decaimento exponencial simples, correspondente a um fenômeno de transferência de massa de $1^{\mathrm{a}}$ ordem.

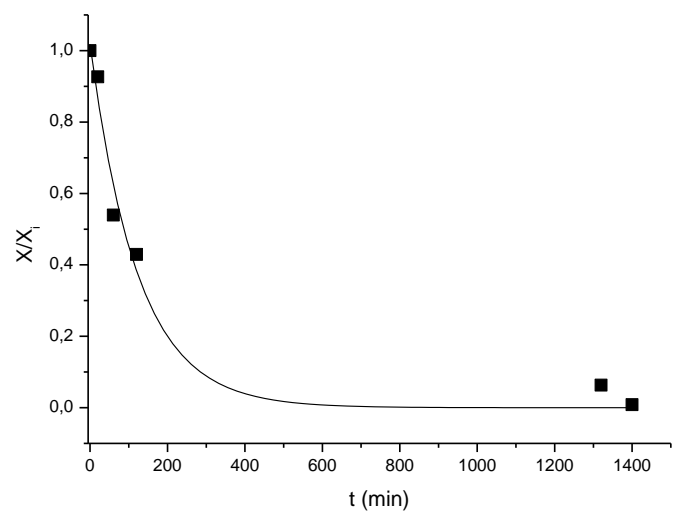

Figura 2 - Modelagem da secagem combinada solar-convectiva. Secagem solar, $\mathrm{T}=37^{\circ} \mathrm{C}$ a 40

${ }^{\circ} \mathrm{C}$. $1^{\mathrm{a}}$ etapa da secagem convectiva: $\mathrm{T}=30^{\circ} \mathrm{C} .2^{\mathrm{a}}$ etapa da secagem convectiva $\mathrm{T}=60^{\circ} \mathrm{C}$.

Nestas condições de operação o valor de umidade final foi muito baixo e por este motivo foi proposta uma abordagem generalizada da curva de secagem combinada, ajustando a evolução no tempo da umidade normalizada com o valor da umidade inicial $\left(X / X_{i}\right)$, de acordo com a Equação 1: 


$$
\frac{X}{X_{i}}=e^{-k t}
$$

O ajuste dos dados experimentais mediante regressão não linear com método de LevenbergMarquardt deu como resultado uma constante de secagem $\mathrm{k}=8,13 \times 10^{-3} \mathrm{~min}^{-1}$ e coeficiente de determinação $\mathrm{R}^{2}=0,980$

Para a secagem combinada constando de duas etapas, solar e convectiva com circulação forçada a $60^{\circ} \mathrm{C}$, as taxas de secagem são bem diferenciadas em cada uma das etapas, como se observa na Figura 1b. Para este caso optou-se por modelar separadamente cada uma das etapas, mostradas nas Figura 3a e $3 \mathrm{~b}$ respectivamente.

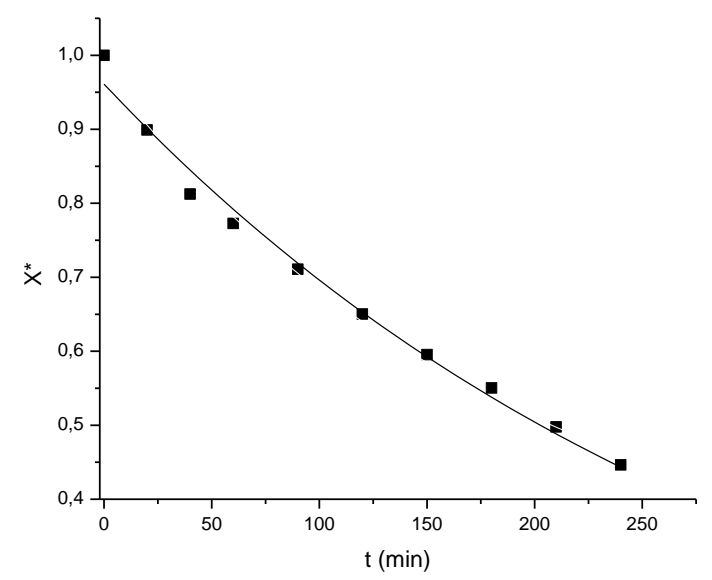

(a)

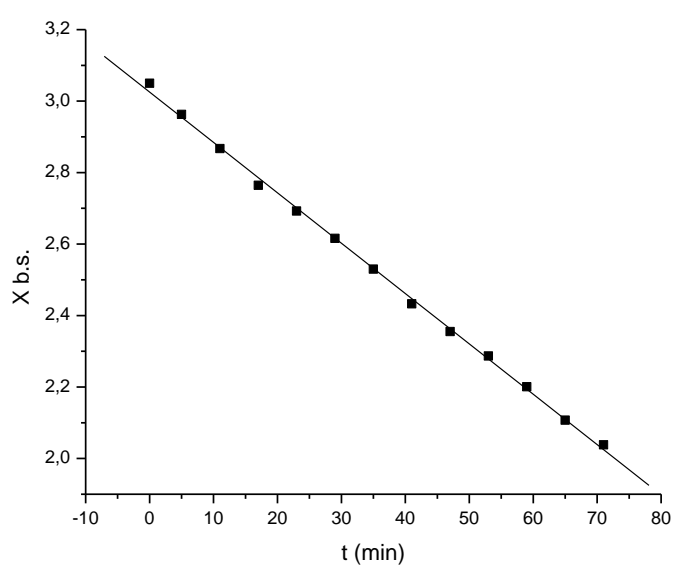

(b)

Figura 3 - Cinética de secagem combinada em duas etapas.

(a) solar. $\mathrm{T}=32^{\circ} \mathrm{C}$. (b) em secador de bandejas com circulação forçada. $\mathrm{T}=60^{\circ} \mathrm{C}$.

Para a etapa solar foi proposto um modelo de $1^{\text {a }}$ ordem para a evolução da razão de umidade $X^{*}$ em função do tempo conforme a Equação 2. O valor de equilíbrio foi obtido mediante extrapolação da curva experimental através da equação de Peleg (1988), obtendo-se $X_{\infty}=2,43$ b.s. A umidade de equilíbrio correspondente à etapa de secagem solar é elevada devido às condições ambientes, com média de umidade relativa do ar de $78 \%$ e temperatura de secagem entre $32{ }^{\circ} \mathrm{C}$ e $40{ }^{\circ} \mathrm{C}$. Este valor indica que durante a etapa de secagem solar, nessas condições suaves, continua o crescimento celular e aponta para a necessidade de uma posterior etapa convectiva, a temperatura mais elevada, para finalização da secagem e inativação da levedura.

$$
X^{*}=\frac{X_{b s}-X_{\infty}}{X_{i}-X_{\infty}}=A_{1} e^{-k_{1} t}
$$


Na Figura 3a são representados os valores da razão de umidade $X^{*}$ em função do tempo e a curva de ajuste pelo modelo exponencial, Equação (2). Os valores dos parâmetros de ajuste da Equação 2 aos dados experimentais, encontrados por regressão não linear pelo método de Levenberg-Marquardt são mostrados na Tabela 2.

Tabela 2 - Parâmetros de ajustes da Equação 2 à curva de secagem na etapa solar

\begin{tabular}{ccc}
\hline$k_{1}\left(\mathrm{~min}^{-1}\right) \times 10^{3}$ & $A_{1}$ & $\mathrm{R}^{2}$ \\
\hline $3,22 \pm 0,1$ & $0,96 \pm 0,01$ & 0,9886 \\
\hline
\end{tabular}

A curva da etapa convectiva, mostrada na Figura $3 b$ sugere que a secagem ocorre a taxa constante, para estas condições de operação. A cinética foi então representada de acordo com a Equação 3.

$$
\frac{d X}{d t}=-k_{2}
$$

O valor da constante de secagem na etapa convectiva no secador de bandejas foi:

$k_{2}=(1,409 \pm 0,016) \times 10^{-2} \min ^{-1}$, com $\mathrm{R}^{2}=0,9986$ e desvio padrão $=0,0127$

Os resultados do ajuste foram adequados para as três situações estudadas, de modo que as equações cinéticas obtidas podem ser consideradas preditivas do processo de secagem.

\subsection{Qualidade do produto}

Na Tabela 3 são mostrados os resultados de caracterização física e química do resíduo in natura, após o enriquecimento e após a secagem, até dois níveis de umidade diferentes, uma amostra com $11,81 \%$ b.u. e outra com $38,60 \%$ b.u., submetidas a diferentes processos combinados de secagem.

Tabela 3 - Análise físico-química do bagaço de abacaxi in natura e enriquecido seco

\begin{tabular}{|c|c|c|c|c|}
\hline Ensaio & Unidade & Amostra1 & Amostra 2 & In natura \\
\hline Valor energético (cálculo) & $\mathrm{kcal} / 100 \mathrm{~g}$ & 333,00 & 231,00 & 61,30 \\
\hline Gordura Total & $\mathrm{g} / 100 \mathrm{~g}$ & 0,64 & 0,28 & 0,13 \\
\hline Umidade & $\mathrm{g} / 100 \mathrm{~g}$ & 11,81 & 38,60 & 84,19 \\
\hline Resíduo Mineral Fixo (Cinzas) & $g / 100 g$ & 5,69 & 3,97 & 0,64 \\
\hline Carboidratos (cálculo) & $g / 100 g$ & 62,46 & 43,75 & 14,21 \\
\hline Proteínas & $g / 100 g$ & 19,40 & 13,40 & 0,83 \\
\hline Brix (sólidos solúveis) a $20{ }^{\circ} \mathrm{C}$ & ${ }^{\circ}$ Brix & 2,15 & 1,90 & 1,15 \\
\hline Açúcares Redutores & $g / 100 g$ & 6,48 & - & 2,88 \\
\hline Açúcares Invertidos & $\mathrm{g} / 100 \mathrm{~g}$ & 4,94 & - & 9,74 \\
\hline Açúcares Totais & $g / 100 g$ & 5,00 & - & 9,40 \\
\hline
\end{tabular}


A etapa de enriquecimento foi conduzida igualmente para ambas as amostras, de acordo com a metodologia. Verifica-se que houve concentração dos nutrientes, pela perda de água, acompanhada de enriquecimento proteico e queda de açúcares, devido ao crescimento celular do microrganismo. O enriquecimento pode ser melhor analisado na Tabela 4, onde os resultados são expressos na base seca. Incluem-se na Tabela 4 os índices de enriquecimento de ambas as amostras para comparação dos processos. Observa-se que para as duas amostras os índices de enriquecimento, foram praticamente os mesmos, indicando que, nas condições brandas de secagem utilizadas, o comportamento é independente do processo de secagem combinado escolhido. Entretanto, a elevada umidade da amostra 2 aponta para a necessidade de uma etapa posterior de secagem, para evitar contaminação e se adequar às normas para suplemento proteico, que estabelecem umidade entre 9 e 12\%. Para as duas amostras o IE proteico foi superior a 4, confirmando ainda o consumo de açúcares para o crescimento celular do microrganismo.

Tabela 4 - Resultados do enriquecimento na base seca

\begin{tabular}{llllll}
\hline Ensaio & in natura & Amostra 1 & Amostra 2 & $\mathrm{IE}_{1}$ & $\mathrm{IE}_{2}$ \\
\hline Umidade (b.s) & 5,32 & 0,13 & 0,63 & - & - \\
Resíduo mineral g/100g (b.s) & 4,05 & 6,46 & 6,47 & 1,6 & 1,6 \\
Carboidratos g/100g (b.s) & 89,88 & 70,90 & 71,25 & 0,79 & 0,79 \\
Proteínas g/100g (b.s) & 5,25 & 22,02 & 21,82 & 4,19 & 4,16 \\
${ }^{\circ}$ Brix (b.s) & 7,27 & 2,44 & 3,09 & 0,34 & 0,43 \\
Açúcares redutores g/100g (b.s) & 18,22 & 7,36 & - & 0,40 & - \\
Açúcares invertidos g/100g (b.s) & 61,61 & 5,61 & - & 0,09 & - \\
Açúcares totais g/100g (b.s) & 59,46 & 5,68 & - & 0,10 & - \\
\hline
\end{tabular}

\section{CONCLUSÕES}

Os resultados obtidos apontam para a viabilidade e vantagens do biorreator secador solar proposto. Verificou-se que o produto obtido a partir do bagaço de abacaxi, apresentou índice de enriquecimento proteico superior a 4,0 sendo comparável a outros resultados disponíveis na literatura. Houve em geral enriquecimento nutricional e energético, tornando o produto atraente como suplemento para alimentação animal. Os níveis de enriquecimento se mostraram independentes do processo de secagem utilizado.

Os processos de secagem combinada solar convectiva realizadas no biorreator secador e finalizadas no secador de bandeja, permitiram manter a qualidade nutricional e, dependendo das condições, obter um produto com níveis de umidade dentro dos limites estabelecidos pelas normas e adequados para um correto armazenamento do material. Os modelos cinéticos propostos apresentaram boa qualidade de ajuste constituindo uma ferramenta útil para a escolha e otimização dos processos combinados. 


\section{AGRADECIMENTOS}

Ao CNPq - Conselho Nacional de Desenvolvimento Científico e Tecnológico pela concessão de bolsas de Iniciação Científica.

\section{REFERÊNCIAS}

ALEXANDRE, H. V.; SILVA, F. L.; GOMES, J.; SILVA, O.; CARVALHO, J.; LIMA, E. Cinética de secagem do resíduo de abacaxi enriquecido. Revista Brasileira de Engenharia Agrícola e Ambiental, v.17, n.6, p.640-646, 2013.

AOAC. Official Methods of Analysis of AOAC International. 18th Edition, William Horwitz and George W. Latimer, Jr., eds. Maryland, USA: AOAC INTERNATIONAL, 2005.

CAMPOS, A. R. N.; SANTANA, R. A. C.; DANTAS, J. P.; OLIVEIRA, S. C.; SILVA, F. L. H.; Enriquecimento proteico do bagaço do pedúnculo de caju por cultivo semi-sólido, Revista de Biologia e Ciências da Terra, v.5, n.2, p. 50-54, set 2005.

FELLOWS, P. Food processing technology. Cambridge: Woodhead Publishing Limited, 2000.

IAL. INSTITUTO ADOLFO LUTZ. Métodos físico-químicos para análise de alimentos. Odair Zenebon, Neus Sadocco Pascuet e Paulo Tiglea (cood). 4. ed. São Paulo: Instituto Adolfo Lutz, 2005.

IBGE. Produção agrícola municipal: culturas temporárias e permanentes. Rio de Janeiro, v. 39, p.1101, 2012.

PANDEY, A.; SOCCOL, C.; LEON, J. A. R. Solid-State fermentation in biotechnology: Fundamentals and applications. 1. Ed. New Delhi: Asiatech Publishers, INC, 2001. 231p.

PELEG, M. An empirical model for the description of moisture sorption curves. Journal of Food Science, 1988, 53 (4), 1216-1219.

PROCREATIN. Aditivo probiótico para alimentação animal. Concentrado termoestável de leveduras vivas. Manual Técnico, 1 ed. 2006. 2p. (BIOSAF).

ROCHA, A.P.T. Estudo do desempenho de um leito e jorro convencional para secagem de leveduras. 2002. Dissertação (Mestrado em Engenharia de Processos Químicos) - Universidade Federal de Campina Grande; Campina grande, PB, 2002.

RODRIGUES, A. M. Efeito do cloreto de sódio na produção de proteínas (Shaccharamyces ceravisiae) em fermentação semi-sólida. Ciência e tecnologia, campinas, v.21, n.1, p.57-62, 2001.

SANTOS, G. dos. Utilização de resíduos agroindustriais para produção de amiloglucosidase por Aspergilus awamori. 2006. 81 f.. Dissertação (Mestrado em Ciência e Tecnologia dos Alimentos) Universidade Estadual de Ponta Grossa, Ponta Grossa, 2006. 